\title{
Gene mutation analysis in 12 Chinese children with congenital nephrotic syndrome
}

\author{
Guo-min Li', Qi Cao', Qian Shen, Li Sun', Yi-hui Zhai ${ }^{1}$, Hai-mei Liu', Yu An² and Hong Xu*
}

\begin{abstract}
Background: Congenital nephrotic syndrome (CNS) is characterised by increased proteinuria, hypoproteinemia, and edema beginning in the first 3 months of life. Recently, molecular genetic studies have identified several genes involved in the pathogenesis of CNS. A systematic investigation of the genes for CNS in China has never been performed; therefore, we conducted a mutational analysis in 12 children with CNS, with the children coming from 10 provinces and autonomous regions in China.

Methods: Twelve children with CNS were enrolled from 2009 to 2016. A mutational analysis was performed in six children by Sanger sequencing in eight genes (NPHS1, NPHS2, PLCE1, WT1, LAMB2, LMXIB, COQ6 and COQ2) before 2014, and whole-exome sequencing was used from 2014 to 2016 in another six children. Significant variants that were detected by next generation sequencing were confirmed by conventional Sanger sequencing in the patients' families.

Results: Of the 12 children, eight patients had a compound heterozygous NPHS1 mutation, one patient had a de novo mutation in the WT1 gene, and another patient with extrarenal symptoms had a homozygous mutation in the COQ6 gene. No mutations were detected in genes NPHS2, PLCE1, LAMB2, LMXIB, and COQ2 in the 12 patients.

Conclusions: This study demonstrates that the majority of CNS cases $(67 \%, 8 / 12$ patients) are caused by genetic defects, and the NPHS1 mutation is the most common cause of CNS in Chinese patients. A mutational analysis of NPHS1 should be recommended in Chinese patients with CNS in all exons of NPHS1 and in the intron-exon boundaries.
\end{abstract}

Keywords: Chinese children, Congenital nephritic syndrome, NPHS1 gene, WT1 gene, COQ6 gene

\section{Background}

Congenital nephrotic syndrome (CNS) is a rare kidney disorder characterised by a high degree of proteinuria, hypoproteinemia, and edema occurring within 3 months after birth [1]. Based on its aetiology, CNS can be divided into primary and secondary disease [2]. The secondary disease is mainly caused by various pathogen infections, such as toxoplasma, syphilis, rubella virus, cytomegalovirus, and herpes simplex virus $[1,2]$. The majority of patients with CNS show mutations in genes encoding key podocyte proteins that constitute the slit diaphragm (NPHS1 and NPHS2); others are expressed in the podocyte membrane (PLCE1), mitochondria, (COQ6,

\footnotetext{
* Correspondence: hxu@shmu.edu.cn

${ }^{1}$ Children's Hospital of Fudan University, 399 Wanyuanlu, Shanghai 201102,

China

Full list of author information is available at the end of the article
}

COQ2) or glomerular basement membrane (LAMB2), and other genes encode transcription factors that are necessary for normal development (WT1, LMX1B) [2-11]. NPHS1 and NPHS2 mutations are the main causes of CNS, but $L A M B 2$ and WT1 mutations have been detected in a few CNS patients in Europe and America $[3,12]$. The NPHS1 mutation is also a major cause of CNS in Japan, but NPHS2 mutations have been found in few CNS patients, and no WT1 mutations have been identified in patients with CNS [13]. A study from South Korea demonstrated that NPHS1 and WT1 mutations are the main causes of CNS and that NPHS2 and $L A M B 2$ mutations are only found in a few patients [14]. In China, mutations of NPHS1, WT1, and LAMB2 were identified in sporadic patients with CNS [15-18], and no other gene mutations were reported in patients with CNS. Case studies involving mutational analyses of 
NPHS1 and LAMB2 are limited, and all of these investigations are case reports [15-17]; in addition, an analysis of a single WT1 mutation was performed in patients with steroid-resistant nephrotic syndrome (SRNS) [18], so it is not clear which gene is the major cause of CNS. In this study, we performed a systematic investigation of genes in 12 children with CNS from 12 unrelated families and from 10 provinces and autonomous regions in China.

\section{Methods \\ Patients}

In total, 12 Chinese CNS patients from 12 unrelated families were enrolled in this study. All patients had the typical clinical findings of both proteinuria and nephrotic syndrome onset between birth and 3 months of age, and there was no evidence of congenital infections. Screenings of the patients' blood sera excluded the presence of antibodies for toxoplasma, syphilis, rubella virus, cytomegalovirus, herpes simplex virus, human immunodeficiency virus (HIV), and Chlamydia trachomatis. All cases were admitted to or followed up at our centre (Children's Hospital of Fudan University) between 2009 and 2016. The study was approved by the Ethics Committee at the Children's Hospital of Fudan University, Shanghai, China. All of the patients' parents provided written informed consents.

\section{DNA sequencing}

The genomic DNA of all patients and their parents was extracted and purified from peripheral leukocytes in whole-blood samples by a DNA isolation kit (Qiagen, Hilden, Germany).

\section{Sanger sequencing}

Sanger sequencing was performed in six children before 2014. All exons of NPHS1, NPHS2, PLCE1, LAMB2, $L M X I B, C O Q 6$, and COQ2, as well as exons 8 and 9 of $W T 1$, were amplified by the polymerase chain reaction (PCR) method. The primers for NPHS1, NPHS2, PLCE1, WT1, LAMB2, LMXIB, COQ6, and COQ2 were designed on the basis of previously published information regarding the intron-exon boundaries $[3,5-8,19,20]$. The PCR products were purified with a QIA Quick PCR Purification Kit (Qiagen, Hilden, Germany). The purified products were cycle-sequenced with Big Dye terminators (Applied Biosystems, Foster City, CA, USA), and the cycle sequence products were analysed with an automated sequencer (ABI Prism 310 Genetic Analyser). The novel mutations were investigated in a number of mutation databases on human populations, such as the ExAC Browser (http://exac.broadinstitute.org/), the $1000 \mathrm{Ge}-$ nomes Project (http://www.internationalgenome.org/), HGMD (http://www.hgmd.cf.ac.uk/ac/index.php), and, in the 100 healthy control subjects, by direct sequencing.

\section{Next generation sequencing}

Whole-exome sequencing was performed in six children with CNS from 2014 to 2016. Targeted exome capture was performed on the genomic DNA from each subject by using the SureSelect Human All Exon Target Enrichment System (Agilent). The captured whole exomes were sequenced on the Illumina HiSeq 2500 Sequencer platform (Illumina, San Diego, CA, USA). A mean exome coverage of $92.68 \times$ was obtained to accurately call variants at $99.51 \%$ of the targeted exome. The read alignment to the human genome assembly hg19 was obtained by using the novoalign alignment tool (Novocraft Technologies). Variant callings and annotations were obtained using the Samtools mpileup utility and Annovar tools, respectively. To obtain the important candidate genes, the resulting variants were systematically annotated and filtered. The program ANNOVAR (http:// www.openbioinformatics.org/annovar/) was used to annotate the variants of the information from various genetic variation databases. Based on the reported variant frequencies, the common variants were first excluded with a minor allele frequency (MAF) greater than 0.01, as represented in the 1000 Genomes Project. According to the variant locations within genes, the variants in the coding regions were given a higher priority, and the variants that altered the coding sequences (nonsynonymous) were selected. The deleteriousness of the selected variants was subsequently predicted by various bioinformatics programs (SIFT, Polyphen2, and NetGene2) (http://genetics.bwh.harvard.edu/pph2/index.shtml; http://sift.jcvi.org/; http://www.cbs.dtu.dk/services/NetGene2), and the variants were retained if their changes to the resulting proteins were damaging.

\section{Results}

\section{Clinical data}

All of the 12 children were initially admitted to our centre due to a high degree of proteinuria and oedema. A renal biopsy was not performed in all children. Of these patients, 9 presented with heavy proteinuria and oedema during the first month of life, and 3 presented with heavy proteinuria and oedema during the first 2 months of life. Six children were male, and six children were female. Only nine children were followed up for 2-3 months, and their proteinuria did not resolve during the follow-up periods. They finally abandoned treatment due to economic reasons and died from complications of infection. Three children (cases 5, 11, and 12) are being followed up in our centre. None of the patients received glucocorticoid therapy, except case 5 , who did not respond to therapy. Case 5 was first diagnosed in 2006, and she was followed up at our centre. This child progressed to end-stage renal disease (ESRD) in 2009, after which she received peritoneal dialysis. She was switched to haemodialysis in 2013, due 
to a loss of peritoneum function, and received a renal transplantation in 2017. Case 11 presented with oedema and proteinuria after his birth. He progressed to end-stage renal disease at the age of nine months and received peritoneal dialysis since that time. A karyotype analysis revealed that he had 46, XY, which is a disorder of sex differentiation. Neither a Wilms tumour or a gonadoblastoma was found during his 3 year follow-up period. Case 12 was a premature infant. A cardiac murmur was found after his birth and continued to be present during his follow-up period. He presented with mild proteinuria at the age of two months. Due to oedema and motor retardation, he was admitted to our hospital for a further assessment at the age of 10 months. Upon admission, a clinical examination revealed that he could not sit, crawl, or even stabilise his head in an upright position. His height was at the third percentile, and his body weight was less than the fifth percentile. Laboratory tests revealed incidences of proteinuria $\left(3+\right.$, total urine protein of $\left.3.28 \mathrm{~g} / \mathrm{m}^{2} / 24 \mathrm{~h}\right)$ and hypoalbuminemia $(22.5 \mathrm{~g} / \mathrm{L})$. An ultrasound showed a pulmonary artery stenosis, a patent ductus arteriosus, an atrial septal defect, an ascending aorta velocity, and a persistent left superior vena cava. He was diagnosed with CNS, congenital heart disease, and motor retardation. At the age of 12 months, she received an oral administration of coenzyme Q10 after a genetic diagnosis. Her proteinuria gradually decreased and was completely in remission $(\mathrm{Up} / \mathrm{Cr} 0.01 \mathrm{mg} / \mathrm{mg})$ after three months of coenzyme Q10 therapy (see Fig. 1). Her motor retardation was also improved by coenzyme Q10 therapy. The clinical features of all patients included in the study are listed in Table 1.

\section{Sanger sequencing}

The pathogenic mutations of NPHS2, PLCE1, WT1, $L A M B 2$, $L M X I B, C O Q 6$, and COQ2 were not found in the 6 children with CNS, but all of the subjects had double heterozygous mutations of NPHS1, as determined by Sanger sequencing (Table 2). A mutational analysis, via Sanger sequencing of the NPHS1 gene in six of the patients' families, showed that all of the mutations were from their parents, respectively.

\section{Next generation sequencing}

Next generation sequencing was performed in the other six children. Two children had compound heterozygous mutations in the NPHS1 gene. Two children had a homozygous mutation in the COQ6 gene and a heterozygous mutation in WT1 gene, respectively (Table 2). No mutations were found in another two children. Mutations in the NPHS1 and COQ6 genes were confirmed by Sanger sequencing. Mutational analyses in those cases' families showed that a c.1334C $>\mathrm{T}$ mutation in the WT1 gene was de novo (Fig. 2) and that other mutations in the NPHS1 and COQ6 genes were from their parents (Table 2 and Fig. 3), respectively.

\section{Functional prediction}

The missense mutations p.D310N and p.R711G were assessed for their potential to disrupt protein function via SIFT and PolyPhen-2, and the predicted results are summarised in Table 2. NetGene2 predicted that a splicing mutation, IVS26DS-2A $>\mathrm{T}$, affected the canonical site for splicing.

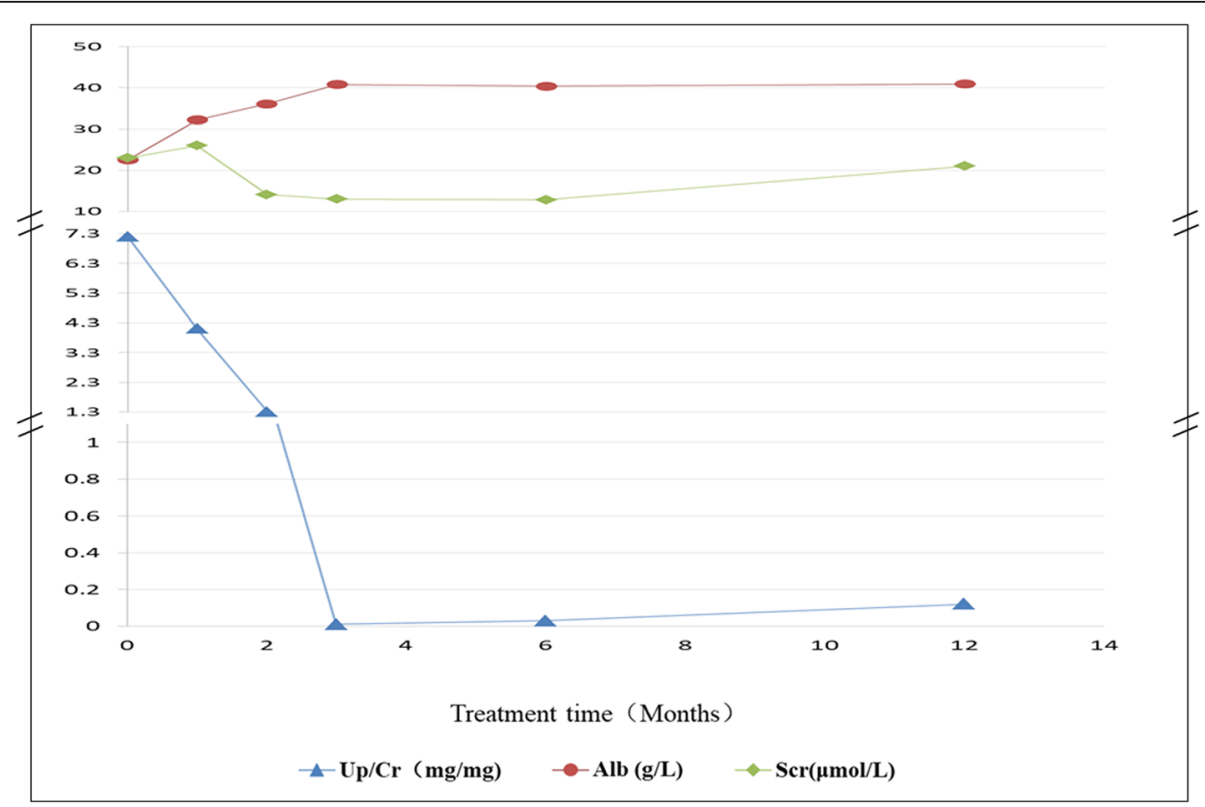

Fig. 1 Change in $U p / C r$, serum albumin, and creatinine after treatment with CoQ10 
Table 1 Clinical features of 12 children with CNS

\begin{tabular}{|c|c|c|c|c|c|c|c|c|c|c|c|c|}
\hline \multirow[t]{2}{*}{ Case } & \multirow[t]{2}{*}{ Age onset } & \multicolumn{4}{|c|}{ Birth history } & \multirow{2}{*}{$\begin{array}{l}\text { Weight of } \\
\text { placenta }\end{array}$} & \multirow[t]{2}{*}{ First symptom } & \multirow{2}{*}{$\begin{array}{l}\text { Proteinuria } \\
\left(\mathrm{g} / \mathrm{m}^{2} / 24 \mathrm{~h}\right)\end{array}$} & \multirow{2}{*}{$\begin{array}{l}\text { Serum albumin } \\
(\mathrm{g} / \mathrm{l})\end{array}$} & \multirow{2}{*}{$\begin{array}{l}\text { Age to } \\
\text { ESRD }\end{array}$} & \multirow[t]{2}{*}{$\mathrm{FH}$} & \multirow[t]{2}{*}{ ES } \\
\hline & & Parity & $\mathrm{GA}(\mathrm{w})$ & $B W(g)$ & Delivery & & & & & & & \\
\hline 1 & At birth & G1P1 & 32 & 2400 & C-sect & $>25 \% \mathrm{BW}$ & Oedema & 6.87 & 12.30 & NA & No & No \\
\hline 2 & $13 \mathrm{D}$ & G1P1 & 33 & 2450 & C-sect & Normal & Oedema & 8.74 & 8.26 & NA & No & No \\
\hline 3 & $3 \mathrm{D}$ & G1P1 & $37^{+2}$ & 2700 & C-sect & Normal & Oedema & 8.28 & 9.85 & NA & No & No \\
\hline 4 & $1.5 \mathrm{M}$ & G1P1 & 38 & NA & NA & Normal & Oedema & 6.32 & 12.8 & NA & No & No \\
\hline 5 & At birth & G2P1 & $37^{+4}$ & 3210 & C-sect & Normal & Oedema & 7.96 & 8.92 & $3 y$ & No & No \\
\hline 6 & At birth & G2P1 & NA & 2760 & N-labor & Normal & Oedema & 7.58 & 10.20 & NA & No & No \\
\hline 7 & At birth & G1P1 & $38^{+4}$ & 3100 & C-sect & Normal & Oedema & 6.92 & 10.50 & NA & No & No \\
\hline 8 & $15 \mathrm{D}$ & G1P1 & 39 & 2850 & C-sect & Normal & Oedema & 2.88 & 28.20 & NA & No & No \\
\hline 9 & At birth & G1P1 & $38^{+5}$ & 3100 & C-sect & Normal & Oedema & 8.63 & 9.65 & NA & No & No \\
\hline 10 & $1 \mathrm{M}$ & G2P1 & $37^{+2}$ & 2880 & N-labor & Normal & Oedema & 7.89 & 11.20 & NA & No & No \\
\hline 11 & At birth & G2P1 & 36 & 2700 & C-sect & Normal & Oedema & 6.28 & 20.1 & $10 \mathrm{~m}$ & No & No \\
\hline 12 & $2 M$ & G1P1 & 38 & 1700 & N-labor & Normal & Oedema & 3.28 & 22.5 & CKD-1 & No & Yes \\
\hline
\end{tabular}

NA not available, BW Birthweight, GA Gestational age, PW Placental weight, C-sect Caesarean section, N-labour natural labour, FH Family history, ES Extrarenal symptom, CKD-1 Chronic kidney disease stage 1,

Table 2 Genotypes of 10 children with CNS

\begin{tabular}{|c|c|c|c|c|c|c|c|c|c|}
\hline \multirow[t]{2}{*}{ Patient } & \multirow[t]{2}{*}{ Exon } & \multirow{2}{*}{$\begin{array}{l}\text { Nucleotide } \\
\text { change }\end{array}$} & \multirow{2}{*}{$\begin{array}{l}\text { amino acid } \\
\text { substitution }\end{array}$} & \multirow[t]{2}{*}{ Mutation type } & \multirow{2}{*}{$\begin{array}{l}\text { Mutation } \\
\text { status }\end{array}$} & \multirow{2}{*}{$\begin{array}{l}\text { Mutation } \\
\text { origin }\end{array}$} & \multirow{2}{*}{$\begin{array}{l}\text { Novel } \\
\text { mutation }\end{array}$} & \multicolumn{2}{|c|}{ Functional effect } \\
\hline & & & & & & & & PolyPhen & SIFT \\
\hline \multicolumn{10}{|c|}{ NPHS1 gene (RS: NM_004646.3) } \\
\hline \multirow[t]{2}{*}{1} & 7 & c. $802 C>T$ & p.R268X & Nonsense & Het & $\mathrm{F}$ & No & - & - \\
\hline & 10 & c. $1528 \mathrm{~A}>\mathrm{C}$ & p.C528G & Missense & Het & M & No & damaging & deleterious \\
\hline \multirow[t]{2}{*}{2} & 20 & c. $2788 \mathrm{C}>\mathrm{T}$ & p.Q930X & Nonsense & Het & $\mathrm{F}$ & Yes & - & - \\
\hline & 27 & c.3442delC & p.Q1148fsX1179 & Frameshift & Het & M & Yes & - & - \\
\hline \multirow[t]{2}{*}{3} & 26 & c. $3325 C>T$ & p.R1109X & Nonsense & Het & M & No & - & - \\
\hline & 27 & c. $3478 C>T$ & p.A1160X & Nonsense & Het & $\mathrm{F}$ & No & - & - \\
\hline \multirow[t]{2}{*}{4} & 13 & $\operatorname{IVS} 12+1 \mathrm{C}>\mathrm{A}$ & NC & Splicing & Het & M & Yes & - & - \\
\hline & 24 & c.3213delG & p.G1071fsX1142 & Frameshift & Het & $\mathrm{F}$ & Yes & - & - \\
\hline \multirow[t]{2}{*}{5} & 26 & c. $3325 C>T$ & p.R1109X & Nonsense & Het & M & No & - & - \\
\hline & 27 & IVS26DS-2A > T & NC & Splicing & Het & $\mathrm{F}$ & Yes & - & - \\
\hline \multirow[t]{2}{*}{6} & 8 & $c .928 \mathrm{G}>\mathrm{A}$ & p.D310N & Missense & Het & $F$ & No & damaging & deleterious \\
\hline & 16 & c. $2131 C>G$ & $\mathrm{p} . \mathrm{R} 711 \mathrm{G}$ & Missense & Het & M & No & damaging & deleterious \\
\hline \multirow[t]{2}{*}{7} & 3 & c. $349 \mathrm{G}>\mathrm{A}$ & p.E117K & Missense & Het & M & No & damaging & deleterious \\
\hline & 8 & $c .928 \mathrm{G}>\mathrm{A}$ & p.D310N & Missense & Het & $\mathrm{F}$ & No & damaging & deleterious \\
\hline \multirow[t]{2}{*}{9} & 10 & c.1550G > T & p.T517K & Missense & Het & $\mathrm{F}$ & Yes & damaging & deleterious \\
\hline & 10 & c. $1559 \mathrm{G}>\mathrm{A}$ & p.S520 L & Missense & Het & M & Yes & damaging & deleterious \\
\hline \multicolumn{10}{|c|}{ WT1 gene (RS: NM_024426.4) } \\
\hline 11 & 8 & c. $1334 C>T$ & p.R445Q & Missense & Het & De novo & Yes & damaging & deleterious \\
\hline \multicolumn{10}{|c|}{ COQ6 gene (RS: NM_182476.2) } \\
\hline 12 & 9 & c. $1078 \mathrm{C}>\mathrm{T}$ & p.R360W & Missense & Hom & Parents & Yes & damaging & deleterious \\
\hline
\end{tabular}




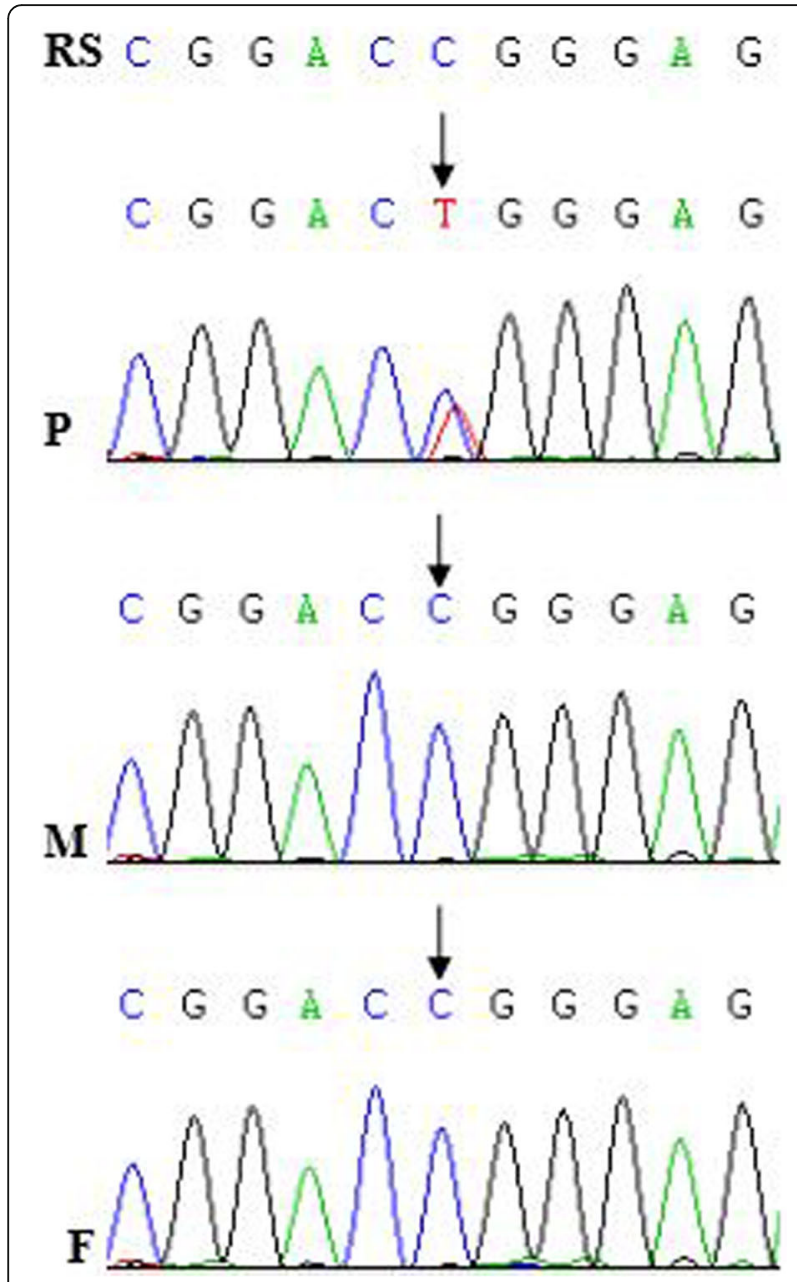

Fig. 2 Mutational analysis in the WT1 gene in the family of case 11 . The sword showed a mutation. P: patient; F: father; M: mother

\section{Discussion}

The frequency of the NPHS1 gene mutation varies among different ethnic groups. In $98 \%$ of children with CNS in Finland, the disease is caused by NPHS1 mutations [21]. Lenkkeri et al. reported that $80 \%(28 / 35)$ of CNS patients from North America, Europe, and North Africa have been identified to harbour mutations in the NPHS1 gene [3]. A study from Europe showed that $84.8 \%(39 / 46)$ of paediatric CNS cases were explained by mutations in four genes. The distribution among these four genes was as follows: NPHS1, 39.8\%; NPHS2, 39.8\%; WT1, 2.2\%; and $L A M B 2,4.4 \%$ [12]. Another study from Europe revealed that $100 \%(15 / 15)$ of paediatric CNS cases were caused by mutations in the NPHS1, NPHS2, and WT1 genes, with frequencies of 80,7 , and $13 \%$, respectively [22]. Furthermore, no mutations of PLCE1 and $L A M B 2$ have been detected [22]. Therefore, NPHS1 is the main gene that causes CNS in Europe and North America. In 2005, a Japanese study showed that 4 out of 15 patients had NPHS1 gene mutations (2 homozygous,

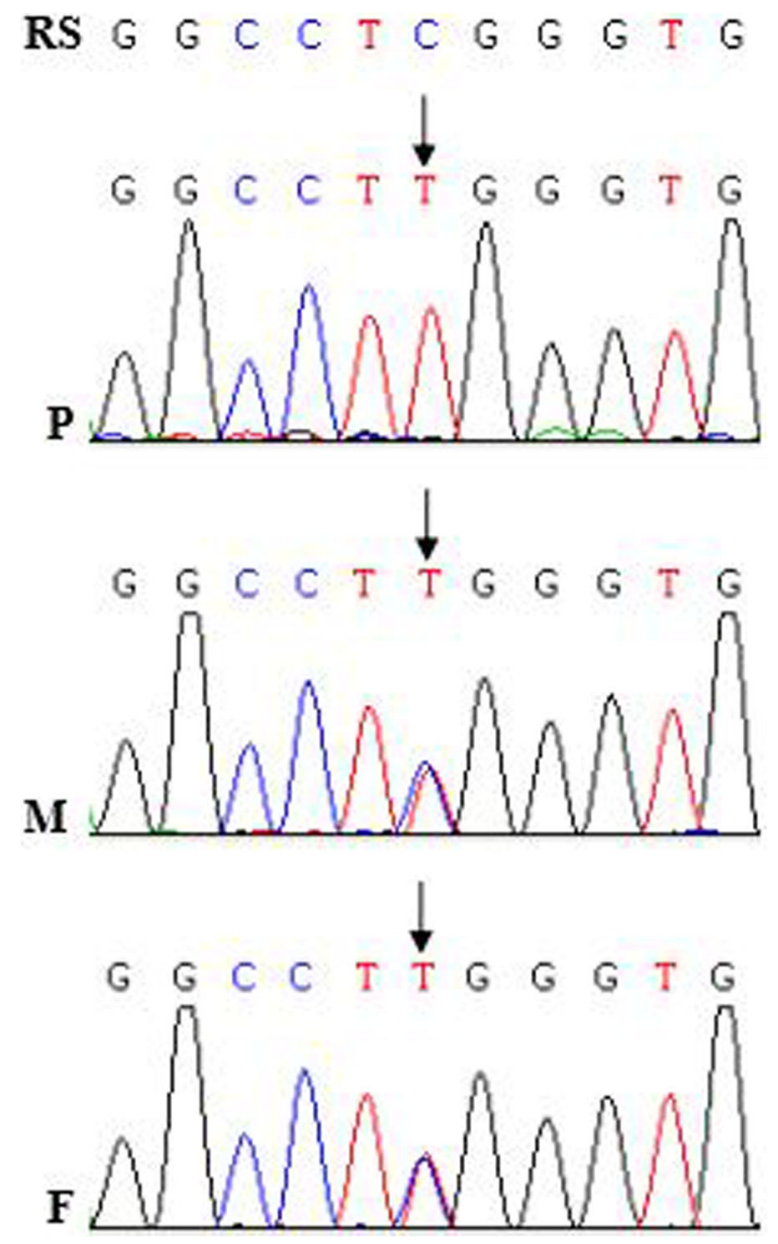

Fig. 3 Mutational analysis in the COQ6 gene in the family of case 12. The sword showed a mutation. P: patient; F: father; M: mother

2 heterozygous), 2 patients had NPHS2 gene mutations ( 1 homozygous, 1 heterozygous), and no patients had WT1 gene mutations [13]. In 2009, another Japanese study reported that 5 out of 5 patients had NPHS1 gene mutations, and the authors considered NPHS1 to be the main causative gene of CNS in Japan [23]. A study from North Korea demonstrated that NPHS1 and WT1 gene mutations were the major causes of $\mathrm{CNS}$ and that NPHS2 and LAMB2 gene mutations were found in only a few CNS patients [14]. An NPHS1 mutation analysis was performed as a case study in China $[15,16]$, with no NPHS2 mutations reported in the Chinese CNS patients. The results of a single-gene analysis in Chinese SRNS patients showed that 1 out of 5 patients with CNS had a WT1 mutation [18]. The number of studies reporting gene analyses of CNS patients is limited in China. Therefore, it is not clear which gene is the main cause of CNS in Chinese patients.

CNS is very rare in China. Mutations of NPHS1, WT1 and $L A M B 2$ were identified in sporadic patients with 
CNS, and all of these investigations are case reports [15-17]. In this study, we performed analyses of NPHS1, NPHS2, PLCE1, WT1, LAMB2, LMXIB, and COQ2 genes by direct sequencing in six Chinese children with CNS and whole exon sequencing (WES) in the other six children. The 12 children were from 12 unrelated families and 10 provinces and autonomous regions in China. Our results showed that eight patients had two heterozygous mutations in the NPHS1 gene, one patient had a homozygous mutation in the COQ6 gene, and one patient had a heterozygous mutation in the WT1 gene. No mutations in any genes associated with nephrotic syndrome and proteinuria syndrome were detected in another two children by WES. The mutations identified by WES were all confirmed by Sanger sequencing. Mutations in the NPHS1 and COQ6 genes in patients were determined to arise from their parents by family analyses. Therefore, eight patients had compound heterozygous mutations in the NPHS1 gene. This finding suggests that the NPHS1 mutation is a major cause of CNS in Chinese patients. Our study only had 12 patients, but this group represented the largest cohort to date in China. An international cohort study in 2015, the largest cohort study performed thus far, revealed that a single-gene caused $69.4 \%$ of cases of SRNS that manifested in children in the first 3 months of life, and it revealed that the distribution of the causative genes was as follows: $40 \%$ for NPHS1, $10.6 \%$ for NPHS2, $8.5 \%$ for WT1, $5.5 \%$ for $L A M B 2$, and $4.7 \%$ for all of the other genes combined [24]. Although there is a difference between our study and the international cohort study on the distribution of causative genes, NPHS1 is a major causative gene of CNS in children in both studies.

$\mathrm{CNS}$ is a recessively inherited disorder that is characterised by a high degree of proteinuria at birth, a large placenta, and a marked oedema within the first 3 months of life [1, 25]. NPHS1 was identified by positional cloning more than two decades ago. The Fin-major (c.121delCT; p.L41 fs) and Fin-minor (c.3325C > T; p.R1109X) mutations account for 78 and $16 \%$ of the mutated alleles, respectively, in Finnish cases; however, these mutations are rarely found in other ethnic groups [3, 4, 26]. In 2002, Koziell et al. reported the incidence of a Turkish CNS patient with a Fin-minor mutation [26]. To date, the Fin-minor mutation has only been reported in the populations of Finland and Turkey. Herein, we also documented the first occurrence of Fin-minor mutations outside of Finland and Turkey. Patient 5 had heterozygous IVS26DS-2A $>\mathrm{T}$ and Fin-minor mutations in intron and exon 26 of NPHS1, which arose from the patient's father and mother, respectively. The IVS26DS-2A > $\mathrm{T}$ mutation was in the splicing junctions and was not found in the 100 control subjects in our study; furthermore, the mutation was in the highly conserved splice signals ('AG'), and the prediction software programmes showed that it had a great effect on the splicing junctions (http://www.cbs.dtu.dk/services/NetGene2). Therefore, we deduced that the mutation affects the splicing process at the cDNA level. Patient 5 also had the typical symptoms of CNS, such as prematurity, a large placenta, a high degree of proteinuria, and rapid progression to ESRD (within 3 years). Two heterozygous nonsense mutations, Fin-minor and p.A1160X, were identified in patient 3 . The p.R1160X mutation, a specific exon 27 nonsense mutation, is predicted to form a truncated protein that lacks the C-terminal 82 amino acids that are implicated in the interaction with podocin. However, patients with CNS caused by the p.R1160X mutation have an unexpectedly milder phenotype, and most of these individuals are females, suggesting a gender effect [27]. Surprisingly, all affected patients are, reportedly, homozygous for this mutation and, among those in whom a renal biopsy is performed, the histologic findings are consistent with CNS [27]. Nevertheless, these patients either have a mild degree of proteinuria or go into remission between the ages of 5and 19-years-old [27]. Patient 3 had serious features of nephrotic syndrome, and no improving trend of the disease during the follow-up period ( 3 months). He might have had a poor prognosis because of his heterozygous p.R1160X and Fin-minor mutations, which is different from patients with homozygous p.R1160X mutations. Our study showed that a Fin-minor mutation was detected in two of the eight CNS patients (25\%) with a NPHS1 mutation. Although our patients were different from those in the Finnish study on race[], a Fin-minor mutation is also a common mutation in our patients.

Of these 12 children, one child (case 12) with extrarenal symptoms had a homozygous c.1078C > T (p.R360W) mutation in the COQ6 gene. The homozygous p.R360W mutation has been not reported before and is damaging for the COQ6 protein, as predicted by the PolyPhen and SIFT software. The COQ6 protein was expressed almost exclusively in the glomeruli, rather than in the tubules [28]. The COQ6 gene mutations that cause a CoQ10 deficiency led to the nephrotic syndrome [28]. The child had been treated with CoQ10 since his genetic diagnosis when he was one year old. His proteinuria was observed to be in complete remission at three months after treatment with $30 \mathrm{mg} /$ (kg.d) CoQ10. It was first instance of a reported mutation in the COQ6 gene in Chinese children with CNS. A heterozygous c.1334C $>\mathrm{T}$ mutation in the WT1gene was detected in case 11 by WES, which was confirmed by Sanger sequencing. Sanger sequencing in the family of case 12 showed that the c.1334C > T (p.R445Q) mutation was de novo, which had been not reported beforehand. Prediction by the PolyPhen and SIFT software displayed the c.1334C $>\mathrm{T}$ mutation as being damaging for the WT1 protein. Case 11 progressed to 
end-stage renal disease shortly after the diagnosis of CNS, and no incidences of sex differentiation disorder, Wilms tumour, and gonadoblastoma was found in this patient to date. Patients with the WT1 mutation not only more frequently presented with chronic kidney disease and hypertension at the time of diagnosis and exhibited a more rapid disease progression but also more frequently had incidences of sex reversal and/or urogenital abnormalities, Wilms tumour, and gonadoblastoma [29]. Therefore, more attention should be paid to this patient, in order to find an occurrence of Wilms tumour and gonadoblastoma in a timely fashion.

Based on our data, which showed that the NPHS1 mutation is the major cause of CNS in Chinese patients, we recommend a NPHS1 analysis in Chinese patients with CNS. Because NPHS1 mutations are distributed among different exons and splicing mutations, a mutational analysis should be performed in all NPHS1 exons, as well as at the boundaries of the introns and exons. However, mutations in several genes can cause CNS. With a decline in sequencing costs, next generation sequencing is an optimal choice for gene screening in patients with $\mathrm{CNS}$, with next generation sequencing including disease targeted sequencing and WES.

\section{Conclusions}

Our study demonstrates that the majority of CNS cases are caused by genetic defects, and the NPHS1 mutation is the most common cause of CNS in Chinese patients. A mutational analysis of NPHS1 should be recommended in Chinese patients with CNS in all exons of NPHS1 and in the intron-exon boundaries.

\section{Abbreviations \\ CNS: Congenital nephrotic syndrome; ESRD: End-stage renal disease; HIV: Human immunodeficiency virus; MAF: Minor allele frequency; PCR: Polymerase chain reactions; WES: Whole exome sequencing}

\section{Acknowledgements}

We thank Jing-xiong Wu and Yi-uv Gong for their invaluable help with the data collection.

\section{Funding}

This work was supported by the Talent Project and the Academic Leader Fostering Project (1125) of the Children's Hospital of Fudan University (Shen).

\section{Availability of data and materials}

The datasets are not publicly available but are available from the first author on reasonable request.

\section{Authors' contribution}

HX, G-mLand YA participated in research design. HX, QC, G-mL, QS, LS and $\mathrm{H}-\mathrm{mL}$ participated in the writing of the paper. QC, G-mL, QS, LS, Y-hZ and $\mathrm{H}-\mathrm{mL}$ participated in the performance of the research. $\mathrm{HX}, \mathrm{G}-\mathrm{mL}$, $\mathrm{Y}$-hZ and YA participated in data analysis. All authors read and approved the final manuscript.

\section{Ethics approval and consent to participate}

The study was approved by the Ethics Committee at the Children's Hospital of Fudan University, Shanghai, China (EKYY-2009-31). All of the patients' parents provided written informed consent.
Consent for publication

Not applicable

\section{Competing interests}

The authors declare that they have no competing interests.

\section{Publisher's Note}

Springer Nature remains neutral with regard to jurisdictional claims in published maps and institutional affiliations.

\section{Author details}

'Children's Hospital of Fudan University, 399 Wanyuanlu, Shanghai 201102, China. ${ }^{2}$ Institutes of Biomedical Sciences of Fudan University, 220 Handanlu, Shanghai 200433, China.

Received: 18 August 2017 Accepted: 11 December 2018

Published online: 29 December 2018

\section{References}

1. Jalanko H. Congenital nephrotic syndrome. Pediatr Nephrol. 2009:24:2121-8.

2. Avni EF, Vandenhoute $K$, Devriendt A, Ismaili $K$, Hackx M, Janssen F, et al. Update on congenital nephrotic syndromes and the contribution of US. Pediatr Radiol. 2011;41:76-81

3. Lenkkeri U, Mannikko M, Mccready P, Lamerdin J, Gribouval O, Niaudet PM, et al. Structure of the gene for congenital nephrotic syndrome of the finnish type (NPHS1) and characterization of mutations. Am J Hum Genet. 1999:64:51-61.

4. Ovunc B, Ashraf S, Vega-Warner V, Bockenhauer D, Elshakhs NA, Joseph M, et al. Mutation analysis of NPHS1 in a worldwide cohort of congenital nephrotic syndrome patients. Nephron Clin Pract. 2012;120:C139-46.

5. Cho HY, Lee JH, Choi HJ, Lee BH, Ha IS, Choi Y, et al. WT1 and NPHS2 mutations in Korean children with steroid-resistant nephrotic syndrome. Pediatr Nephrol. 2008;23:63-70.

6. Boute N, Gribouval O, Roselli S, Benessy F, Lee H, Fuchshuber A, et al. NPHS2, encoding the glomerular protein podocin, is mutated in autosomal recessive steroid-resistant nephrotic syndrome. Nat Genet. 2000;24:349-54.

7. Boyer O, Benoit G, Gribouval O, Nevo F, Pawtowski A, Bilge I, et al. Mutational analysis of the PLCE1 gene in steroid resistant nephrotic syndrome. J Med Genet. 2010;47(7):445-52.

8. Diomedi-Camassei F, Di Giandomenico S, Santorelli FM, Caridi G, Piemonte F, Montini G, et al. COQ2 nephropathy: a newly described inherited mitochondriopathy with primary renal involvement. J Am Soc Nephrol. 2007;18:2773-80.

9. Chen YM, Zhou Y, Go G, Marmerstein JT, Kikkawa Y, Miner JH. Laminin beta2 gene missense mutation produces endoplasmic reticulum stress in podocytes. J Am Soc Nephrol. 2013;24:1223-33.

10. Hakan N, Aydin M, Erdogan O, Cavusoglu YH, Aycan Z, Ozaltin F, et al. A novel WT1 gene mutation in a newborn infant diagnosed with Denys-Drash syndrome. Genet Couns. 2012;23:255-61.

11. Kopp JB. An expanding universe of FSGS genes and phenotypes: LMX1B mutations cause familial autosomal dominant FSGS lacking extrarenal manifestations. J Am Soc Nephrol. 2013;24:1183-5.

12. Hinkes BG, Mucha B, Vlangos CN, Gbadegesin R, Liu J, Hasselbacher K, et al. Nephrotic syndrome in the first year of life: two thirds of cases are caused by mutations in 4 genes (NPHS1, NPHS2, WT1, and LAMB2). Pediatrics. 2007; 119(4):e907-19.

13. Sako M, Nakanishi K, Obana M, Yata N, Hoshii S, Takahashi S, et al. Analysis of NPHS1, NPHS2, ACTN4, and WT1 in Japanese patients with congenital nephrotic syndrome. Kidney Int. 2005;67:1248-55.

14. Lee $\mathrm{H}$, Han KH, Lee H, Kang HG, Moon KC, Shin Jl, et al. Genetic basis of congenital and infantile nephrotic syndromes. Am J Kidney Dis. 2011;58: 1042-3

15. Wu LQ, Hu JJ, Xue JJ, Liang DS. Two novel NPHS1 mutations in a Chinese family with congenital nephrotic syndrome. Genet Mol Res. 2011;10:2517-22

16. Yu ZH, Wang DJ, Meng DC, Huang J, Nie XJ. Mutations in NPHS1 in a Chinese child with congenital nephrotic syndrome. Genet Mol Res. 2012;11: $1460-4$

17. Zhao D, Ding J, Wang F, Fan Q, Guan N, Wang S, et al. The first Chinese Pierson syndrome with novel mutations in LAMB2. Nephrol Dial Transplant. 2010;25:776-8. 
18. Li J, Ding J, Zhao D, Yu Z, Fan Q, Chen Y, et al. WT1 gene mutations in Chinese children with early onset nephrotic syndrome. Pediatr Res. 2010;68:155-8.

19. Zenker M, Aigner T, Wendler O, Tralau T, Müntefering H, Fenski R, et al. Human laminin beta2 deficiency causes congenital nephrosis with mesangial sclerosis and distinct eye abnormalities. Hum Mol Genet. 2004;13: 2625-32.

20. Knoers NV, Bongers EM, van Beersum SE, Lommen EJ, van Bokhoven H, Hol FA. Nail-patella syndrome: identification of mutations in the LMX1B gene in Dutch families. J Am Soc Nephrol. 2000;11:1762-6.

21. Patrakka J, Kestila M, Wartiovaara J, Ruotsalainen V, Tissari P, Lenkkeri U, et al. Congenital nephrotic syndrome (NPHS1): features resulting from different mutations in Finnish patients. Kidney Int. 2000;58:972-80.

22. Santin S, Bullich G, Tazon-Vega B, García-Maset R, Giménez I, Silva I, et al, Clinical utility of genetic testing in children and adults with steroid-resistant nephrotic syndrome. Clin J Am Soc Nephrol. 2011;6:1139-48.

23. Aya K, Shimizu J, Ohtomo Y, Satomura K, Suzuki H, Yan K, et al. NPHS1 gene mutation in Japanese patients with congenital nephrotic syndrome. Nephrol Dial Transplant. 2009;24:2411-4.

24. Sadowski CE, Lovric S, Ashraf S, Pabst WL, Gee HY, Kohl S, et al. A singlegene cause in $29.5 \%$ of cases of steroid-resistant nephrotic syndrome. J Am Soc Nephrol. 2015;26:1279-89.

25. Tikhomirov E, Averyanova N, Voznesenskaya T, Voznesenskaya T, Tsygin A. Gene symbol: NPHS1. Disease: congenital nephrotic syndrome, Finnish type. Hum Genet. 2008;124:304-8.

26. Schoeb DS, Chernin G, Heeringa SF, Matejas V, Held S, Vega-Warner V, et al. Nineteen novel NPHS1 mutations in a worldwide cohort of patients with congenital nephrotic syndrome (CNS). Nephrol Dial Transplant. 2010;25:2970-6.

27. Koziell A, Grech V, Hussain S, Lee G, Lenkkeri U, Tryggvason K, et al. Genotype/phenotype correlations of NPHS1 and NPHS2 mutations in nephrotic syndrome advocate a functional inter-relationship in glomerular filtration. Hum Mol Genet. 2002;11:379-88.

28. Heeringa SF, Chernin G, Chaki M, Zhou W, Sloan AJ, Ji Z, et al. COQ6 mutations in human patients produce nephrotic syndrome with sensorineural deafness. J Clin Invest. 2011;121(5):2013-24.

29. Lipska BS, Ranchin B, latropoulos P, Gellermann J, Melk A, Ozaltin F, et al. Genotype-phenotype associations in WT1 glomerulopathy. Kidney Int. 2014; 85:1169-78.

Ready to submit your research? Choose BMC and benefit from:

- fast, convenient online submission

- thorough peer review by experienced researchers in your field

- rapid publication on acceptance

- support for research data, including large and complex data types

- gold Open Access which fosters wider collaboration and increased citations

- maximum visibility for your research: over $100 \mathrm{M}$ website views per year

At BMC, research is always in progress.

Learn more biomedcentral.com/submissions 